\title{
The logic of kinetic regulation in the thioredoxin system
}

\author{
Ché S Pillay ${ }^{1 *}$, Jan-Hendrik S Hofmeyr ${ }^{2,3}$, Johann M Rohwer ${ }^{2}$
}

\begin{abstract}
Background: The thioredoxin system consisting of $\operatorname{NADP}(\mathrm{H})$, thioredoxin reductase and thioredoxin provides reducing equivalents to a large and diverse array of cellular processes. Despite a great deal of information on the kinetics of individual thioredoxin-dependent reactions, the kinetic regulation of this system as an integrated whole is not known. We address this by using kinetic modeling to identify and describe kinetic behavioral motifs found within the system.
\end{abstract}

Results: Analysis of a realistic computational model of the Escherichia coli thioredoxin system revealed several modes of kinetic regulation in the system. In keeping with published findings, the model showed that thioredoxindependent reactions were adaptable (i.e. changes to the thioredoxin system affected the kinetic profiles of these reactions). Further and in contrast to other systems-level descriptions, analysis of the model showed that apparently unrelated thioredoxin oxidation reactions can affect each other via their combined effects on the thioredoxin redox cycle. However, the scale of these effects depended on the kinetics of the individual thioredoxin oxidation reactions with some reactions more sensitive to changes in the thioredoxin cycle and others, such as the Tpx-dependent reduction of hydrogen peroxide, less sensitive to these changes. The coupling of the thioredoxin and Tpx redox cycles also allowed for ultrasensitive changes in the thioredoxin concentration in response to changes in the thioredoxin reductase concentration. We were able to describe the kinetic mechanisms underlying these behaviors precisely with analytical solutions and core models.

Conclusions: Using kinetic modeling we have revealed the logic that underlies the functional organization and kinetic behavior of the thioredoxin system. The thioredoxin redox cycle and associated reactions allows for a system that is adaptable, interconnected and able to display differential sensitivities to changes in this redox cycle. This work provides a theoretical, systems-biological basis for an experimental analysis of the thioredoxin system and its associated reactions.

\section{Background}

The thioredoxin redox cycle consisting of $\operatorname{NADP}(\mathrm{H})$, thioredoxin reductase and thioredoxin is central to the regulation of several cellular redox processes [1-4]. Thioredoxin reductase reduces the oxidized form of thioredoxin with NADPH as a source of reducing equivalents (Figure 1). Reduced thioredoxin in turn reduces a diverse array of cellular redox partners which are essential in a number of cellular processes such as hydrogen peroxide metabolism, sulfate assimilation, DNA synthesis and signal transduction [1-3,5].

\footnotetext{
*Correspondence: pillayc3@ukzn.ac.za

'Discipline of Genetics, University of KwaZulu-Natal, South Africa, Carbis

Road, Pietermaritzburg, 3201, South Africa

Full list of author information is available at the end of the article
}

The kinetics of individual thioredoxin-dependent reactions have been studied in great detail; parameters and kinetic models (mass action, ping-pong and redox cycles) are available for many reactions. However, the kinetic regulation of the thioredoxin system as a whole is not known. While kinetic modeling would be the ideal tool to explore this type of regulation, the contrasting in vivo and in vitro descriptions given to thioredoxins have complicated the construction of models of the thioredoxin system. Redox potentials have been used to describe the thioredoxin system in vivo (see for example [6]), which has led to the description of redoxin networks as redox circuits in which thioredoxin is a central node that distributes reducing equivalents to a number of independent processes (Figure 1, [3,7]). On the other 


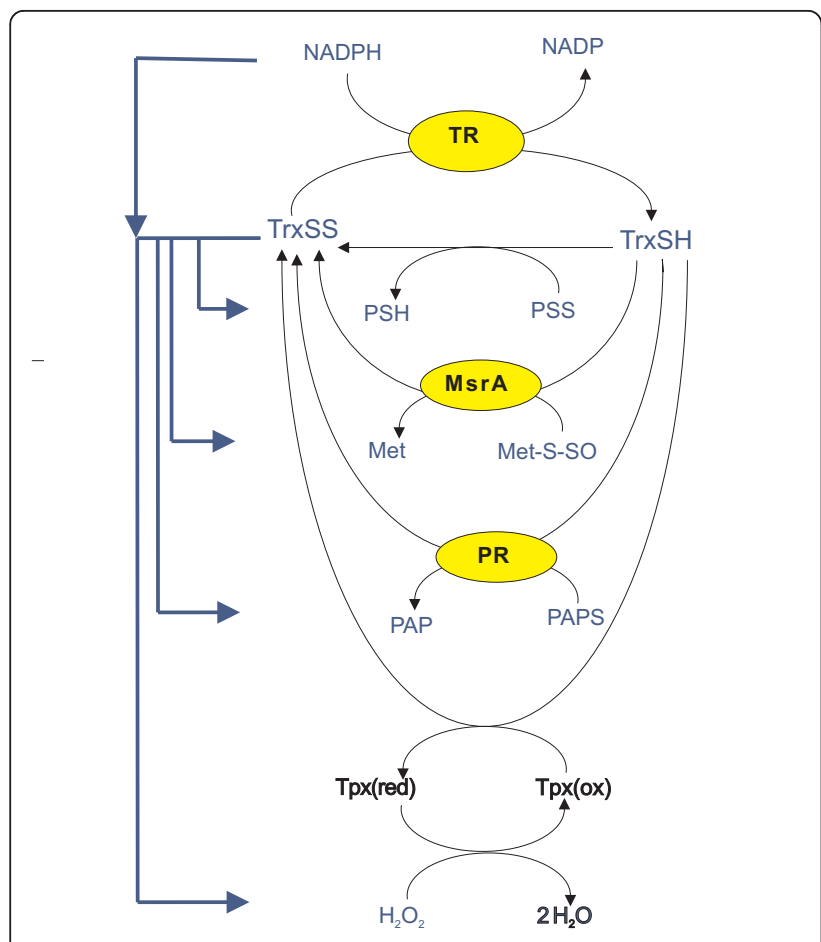

Figure 1 Modelling the thioredoxin system in $\mathrm{E}$. coli. A kinetic model of the thioredoxin system in E. coli was developed that included reactions for the reduction of oxidized thioredoxin (TrxSS) by thioredoxin reductase (TR), the thioredoxin-dependent reductions of methionine sulfoxide (Met-S-SO) by methionine sulfoxide reductase (MsrA) and 3'-phosphoadenosine-5'-phosphosulfate (PAPS) by PAPS reductase (PR) and the Tpx-dependent reduction of hydrogen peroxide. In other systems biology approaches, electron flow pathways have been used to model this system (blue arrows). However, in our model, thioredoxin-dependent reactions were modeled as a series of moiety conserved cycles (see text for details).

hand, thioredoxins have also exhibited enzymatic behaviors such as substrate saturation in vitro (see for example [8]), which suggested that Michaelis-Menten parameters were the key descriptors for thioredoxin activity and these parameters have consequently been used to delineate the roles played by individual redoxins in cellular process (see for example [9]). We have recently reconciled these in vitro and in vivo descriptions by showing that the purported enzymatic properties attributed to thioredoxins resulted from the saturation of the thioredoxin redox cycle and that the ratio of reduced to oxidized thioredoxin reflects the steady state rates of thioredoxin reduction and oxidation [10].

A further challenge for any systems analysis of thioredoxin system is that there is as yet no solid theoretical framework on which to be base such an analysis. It is not clear, for example, whether thioredoxin-dependent reactions affect each other, or how the kinetic structures within the thioredoxin system contribute to the regulation of the system. In this paper we address this by analyzing a set of kinetically distinct reactions from the thioredoxin system in Escherichia coli (Figure 1). Using kinetic modeling we precisely describe how changes in the thioredoxin redox cycle affect thioredoxin-dependent reactions and show that the kinetic behavioral motifs found within the thioredoxin system and associated reactions allow for several modes of kinetic regulation.

\section{Results}

Kinetic model of the Escherichia coli thioredoxin system

To identify putative kinetic motifs within the thioredoxin system, a realistic computational model of the E. coli thioredoxin system was developed. However, the kinetic parameters for many of the reactions involved in the complete thioredoxin redox network were unavailable or may require revision [10] and we therefore only modeled a set of thioredoxin-dependent reactions (Figure 1, Table 1). To simplify the description of the results below, reduced thioredoxin ( $\operatorname{Trx} 1)$ will be referred to as "thioredoxin" and oxidized thioredoxin will be referred to as "oxidized thioredoxin". Trx2 was not included in the model as its intracellular concentration is substantially lower than Trx1 even under oxidative stress conditions [11].

In this model, the reduction of oxidized thioredoxin by thioredoxin reductase was assigned Michaelis-Menten kinetics and the non-specific reduction of cytosolic protein disulfides (PSS) was modeled with mass action kinetics as previously described [10]. Thioredoxin is an electron donor for the reduction of methionine sulfoxide and 3'-phosphoadenosine-5'-phosphosulfate (PAPS) by methionine sulfoxide and PAPS reductase respectively [5] which both utilize a ping-pong kinetic mechanism [12-14]. However, the concentration for PAPS in our model was lower than the assigned concentration of PAPS reductase (Table 1) and this reaction was therefore modeled with mass action kinetics. The model included the reduction of the peroxiredoxin Tpx by thioredoxin and its oxidation by hydrogen peroxide [15].

Peroxiredoxins have generally been regarded as enzymes and their activities have usually been described with Michaelis-Menten parameters (see for example [15]). However, this description of peroxiredoxin activity is undergoing review for a number of reasons. Firstly, intracellular peroxiredoxin concentrations are usually much greater than the ambient intracellular hydrogen peroxide concentration in cells [16]. Secondly, it has been shown that Michaelis-Menten parameters in general [17] and some assay conditions specifically [18] have underestimated the activity of peroxiredoxins. Dalziel kinetic analysis has also shown that the peroxiredoxin reduction and oxidation reactions for Schistosoma 
Table 1 Kinetic parameters and metabolite concentrations used in a computational model of the E. coli thioredoxin system

\begin{tabular}{|c|c|c|}
\hline & Value & Reference \\
\hline Metabolites & $(\mu \mathrm{M})$ & \\
\hline NADPH & 137 & {$[61]$} \\
\hline NADP & 1 & - \\
\hline TrxSH & 1 & {$[62]^{a}$} \\
\hline TrxSS & 1 & {$[62]^{a}$} \\
\hline PSS & 4.23 & $b$ \\
\hline PSH & 1 & - \\
\hline MetSO & 970 & $b$ \\
\hline Met & $4.83 \times 10^{4}$ & $b$ \\
\hline PAPS & 0.07 & {$[59]^{b, c}$} \\
\hline $\mathrm{SO}_{3}{ }^{2-}$ & 1 & - \\
\hline PAP & 1 & - \\
\hline $\mathrm{H}_{2} \mathrm{O}_{2}$ & 0.02 & {$[27,28]$} \\
\hline $\mathrm{H}_{2} \mathrm{O}$ & 1 & - \\
\hline \multicolumn{3}{|l|}{ Thioredoxin } \\
\hline \multicolumn{3}{|l|}{ reductase } \\
\hline [TR] & $4.74 \mu \mathrm{M}$ & {$[50]$} \\
\hline$k_{\text {cat }}$ & $22.75 \mathrm{~s}^{-1}$ & {$[63]$} \\
\hline$K_{\text {nadph }}$ & $1.2 \mu \mathrm{M}$ & [64] \\
\hline$K_{\text {trxss }}$ & $2.8 \mu \mathrm{M}$ & [64] \\
\hline \multicolumn{3}{|l|}{ PSS reduction } \\
\hline$k_{2}$ & $0.064 \mu \mathrm{M}^{-1} \mathrm{~s}^{-1}$ & [10] \\
\hline \multicolumn{3}{|c|}{ Methionine sulfoxide } \\
\hline \multicolumn{3}{|l|}{ reductase } \\
\hline$[\mathrm{MsrA}]$ & $2.35 \mu \mathrm{M}$ & $b$ \\
\hline$k_{\text {cat }}$ & $3.7 \mathrm{~s}^{-1}$ & {$[12]$} \\
\hline$K_{\text {metso }}$ & $1900 \mu \mathrm{M}$ & [12] \\
\hline$K_{\text {trxsh }}$ & $10 \mu \mathrm{M}$ & {$[12]$} \\
\hline \multicolumn{3}{|c|}{ PAPS reductase } \\
\hline$[\mathrm{PR}]$ & $0.345 \mu \mathrm{M}$ & b \\
\hline$k_{\text {cat }}$ & $3.5 \mathrm{~s}^{-1}$ & [14] \\
\hline$K_{\text {paps }}$ & $22.5 \mu \mathrm{M}$ & [14] \\
\hline$K_{\text {trxsh }}$ & $13.7 \mu \mathrm{M}$ & [14] \\
\hline$k_{\mathrm{pr}}$ & $0.156 \mu \mathrm{M}^{-1} \mathrm{~s}^{-1}$ & $b$ \\
\hline \multicolumn{3}{|l|}{ Tpx } \\
\hline$[\mathrm{Tpx}]$ & $4.88 \mu \mathrm{M}$ & {$[57]$} \\
\hline$k_{\mathrm{H} 2 \mathrm{O} 2}$ & $44 \mu \mathrm{M}^{-1} \cdot s^{-1}$ & [15] \\
\hline$k_{\mathrm{tr} \times s h}$ & $3000 \mu \mathrm{M}^{-1} \cdot \mathrm{s}^{-1}$ & {$[15]$} \\
\hline
\end{tabular}

${ }^{a}$ Total thioredoxin concentration (TrxSH + TrxSS) obtained from [62].

bDiscussed in Methods "Realistic. model of the E. coli thioredoxin system".

c Estimated from bakers yeast.

A realistic computational model of the E. coli thioredoxin system (Figure 1) containing reactions for the reduction of methionine sulfoxide (MetSO) by methionine sulfoxide reductase $A(M s r A)$, the reduction of $3^{\prime}-$

phosphoadenosine- $5^{\prime}$-phosphosulfate (PAPS) to adenosine- $3^{\prime}-5^{\prime}-$ bisphosphate (PAP) by PAPS reductase, the reduction of the $\mathrm{H}_{2} \mathrm{O}_{2}$ by Tpx and thioredoxin, the reduction of cellular protein disulfides (PSS) to protein thiols (PSH) by thioredoxin and a thioredoxin reductase reaction was developed. Fixed parameters whose values did not affect the model outputs were set to $1 \mu \mathrm{M}$. mansoni peroxiredoxin 1 can essentially be described by two independent mass action reactions [19], and, in a model of hemoglobin oxidation in red cells, the reduction of hydrogen peroxide by peroxiredoxin II could be modeled effectively with mass action kinetics [20]. In our computational model, the individual oxidation and reduction reactions of Tpx were therefore described with mass action kinetics (i.e. the peroxiredoxin redox cycle was modeled explicitly, see Figure 1).

To analyze this system, model parameters were varied and the effect of these changes on the fluxes through the thioredoxin system was determined [21,22] (Figure 2). Decreases in the concentration of thioredoxin reductase triggered decreases in the fluxes of all thioredoxin-dependent reactions showing that the kinetic profiles for all reactions that yield oxidized thioredoxin can be affected by global changes in the thioredoxin system (Figure 2A). However, the extent of these decreases differed between these reactions with the flux through the Tpx being the least affected and the fluxes for the non-specific reduction of protein disulfides (PSS) and the reduction of PAPS being the most affected.

A decrease in the thioredoxin reductase concentration decreased the steady state (reduced) thioredoxin concentration (Figure 2B), consequently affecting the fluxes of the thioredoxin oxidation reactions (Figure 2A). These results agree with published findings which have shown that changes in the thioredoxin system can change the oxidation state of thioredoxin (see for example [23]) and therefore affect thioredoxin-dependent pathways [3,6,23-25]. A striking feature of these changes to the thioredoxin reductase levels was the abrupt, almost ultrasensitive change [26] in the reduced thioredoxin concentration (Figure 2B).

In this model, increases in the protein disulfide concentration (PSS) increased the fluxes through the thioredoxin reductase and the protein disulfide reduction reactions (Figure 2C), with the latter reaction saturating at higher concentrations of substrate (not shown) whilst the other reactions were not as affected over the range of concentrations tested in this analysis (Figure 2C). Increases in the substrate concentrations for the PAPS and methionine sulfoxide reductases also increased their fluxes whilst the fluxes of the other thioredoxin oxidation reactions were not dramatically affected (Figure 2D-E). On the other hand, increases in the hydrogen peroxide levels substantially decreased the fluxes through the other thioredoxin oxidation reactions whilst having a smaller effect on the fluxes though the Tpx and the thioredoxin reductase reactions, indicating that the system has a differential sensitivity to hydrogen 


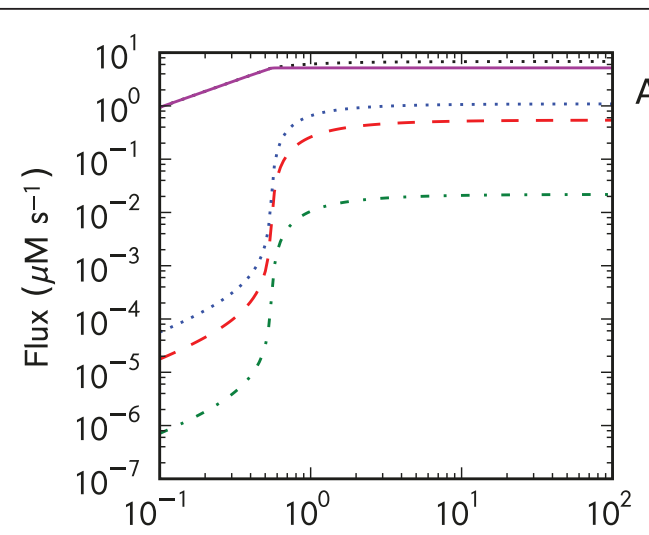

$[\mathrm{TR}](\mu \mathrm{M})$
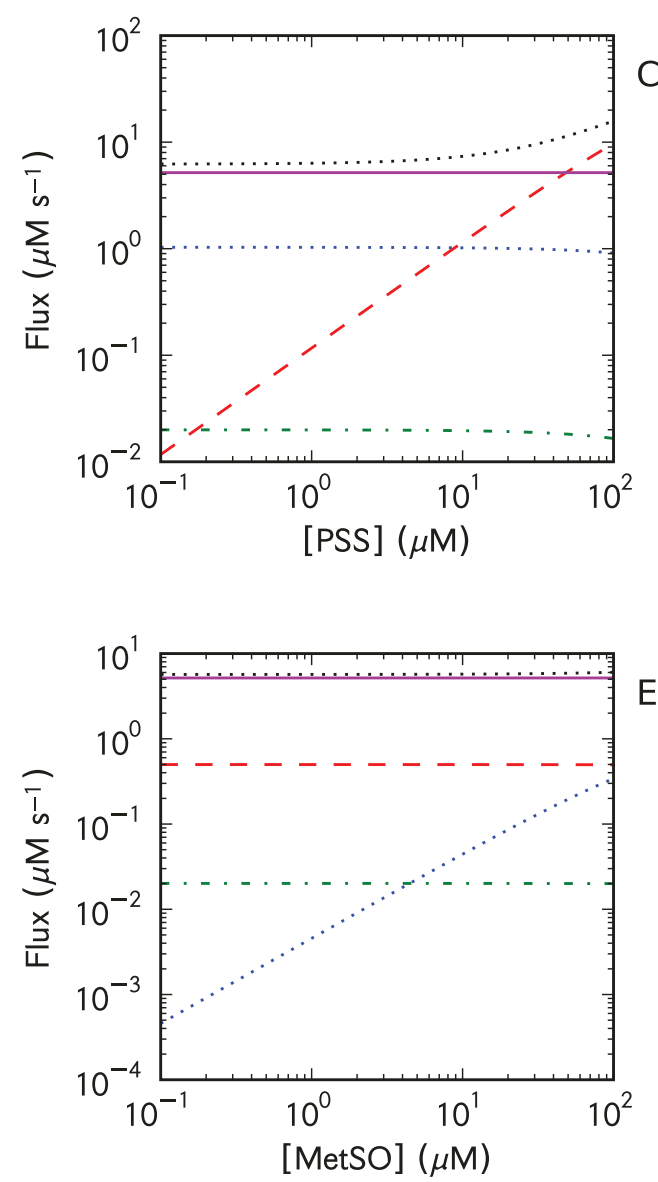
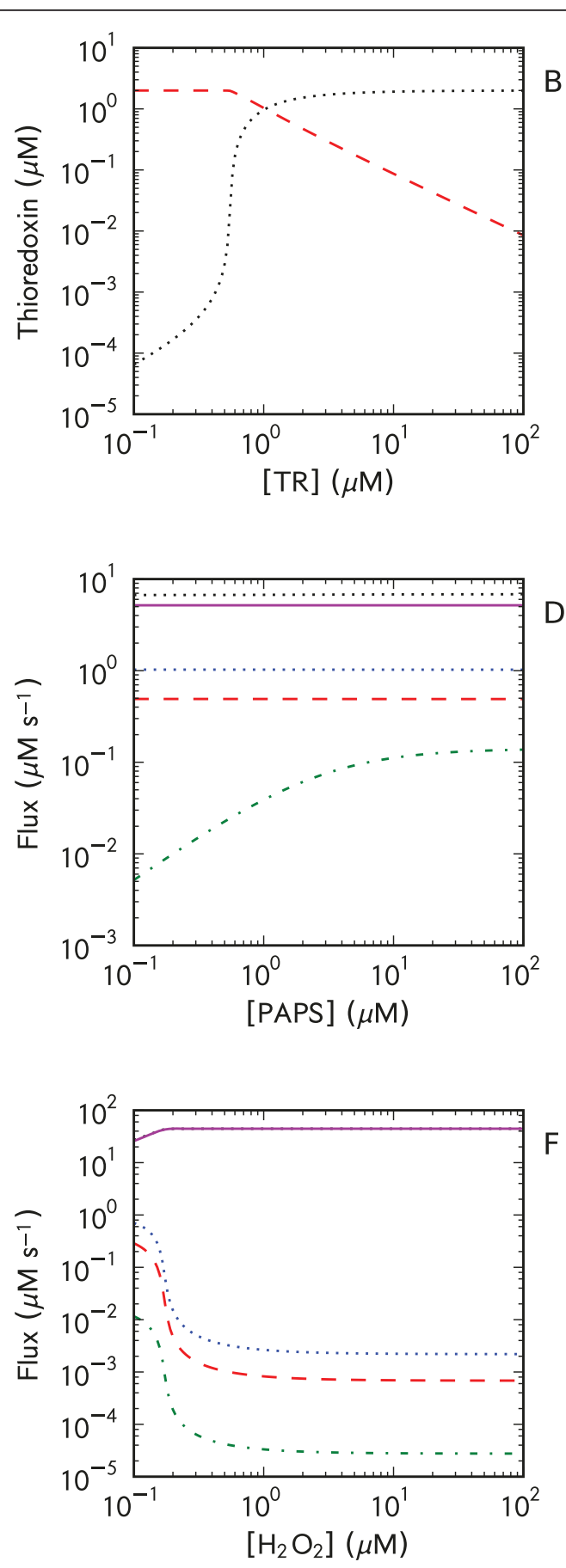

Figure 2 Parameter portraits of the systemic behavior of a computational model of the $E$. coli thioredoxin system. Changes in the thioredoxin reductase (TR) concentration affected the fluxes of thioredoxin-dependent reactions (A) and the steady state thioredoxin (blue, $\cdot$ ) and oxidized thioredoxin concentrations (red, -) (B) in the model. Similarly, changes in the protein disulfide (C), PAPS (D), methionine sulfoxide (E) and hydrogen peroxide (F) concentrations also affected the fluxes through the system. The PAPS reductase reaction was modeled with mass action kinetics (Figures 2 A-C, E-F) or with ping-pong kinetics (Figure 2D) (see Methods for details). The fluxes shown are thioredoxin reductase (black, -..), protein disulfide reduction (red, - ), methionine sulfoxide reductase (blue, -..), PAPS reductase (green, --) and Tpx (magenta, -). Parameters are summarized in Table 1. This figure was generated using 'Logic_Figure 2_and Figure 4.psc' (Additional file 1) and 'Logic_Figure 2 D.psc' (Additional file 2). SBML versions of these models, 'Logic_Figure 2_and Figure 4.xml' (Additional file 5) and 'Logic_Figure 2 D.xml' (Additional file 6), are provided as well. 
peroxide (Figure 2F). These results demonstrate that, depending on its kinetics, a given thioredoxin-dependent reaction may be significantly affected by, or may significantly affect other thioredoxin-dependent reactions.

Based on these results we have identified four kinetic behaviors that could potentially regulate the fluxes through the thioredoxin system. Firstly, the system appears to be adaptable, i.e. changes in the thioredoxin system can result in different kinetic profiles for thioredoxin-dependent reactions (Figure 2A). Secondly, the (reduced) thioredoxin concentration appears to respond in an ultrasensitive manner to changes in the thioredoxin reductase concentration (Figure 2B). Thirdly, reactions involving thioredoxin display varying degrees of interconnectivity to each other by virtue of their combined effects on the thioredoxin redox cycle (Figure 2B, C, E). Finally, depending on their kinetics, individual thioredoxin-dependent reactions may be either insulated or sensitive to changes in the thioredoxin redox cycle (Figure 2C-F). Analytical solutions and computational models were used to investigate the principles underlying these behaviors.

\section{Adaptable systems}

Michaelis-Menten parameters obtained from enzymekinetic assays of thioredoxin in vitro are not true constants - they have been shown to vary with changes in the concentration of the components of the thioredoxin system (Table 1, [8] and see [10]). Furthermore, changes to the thioredoxin system in vivo affect the fluxes through thioredoxin-dependent reactions [3,6,11]. These results together with our modeling data (Figure 2A) suggested that changes to the thioredoxin system can affect the kinetic profiles of thioredoxin oxidation reactions. To describe this effect in more detail an analytical solution for a single cycle redoxin system with irreversible mass action kinetics for all reactions was evaluated (Scheme I). Mass action kinetic expressions were used since realistic treatments with Michaelis-Menten or ternary complex expressions for thioredoxin reductase [10] were not solvable analytically. Nonetheless these simplified solutions have showed a good correspondence to models with realistic kinetic parameters and rate expressions [10].

\section{Scheme I}

$$
\begin{aligned}
& N A D P H+\operatorname{Tr} x S S \rightarrow N A D P+\operatorname{Tr} x S H \\
& \operatorname{Tr} x S H+P S S \rightarrow \operatorname{Tr} x S S+P S H
\end{aligned}
$$

In this scheme, reaction (1) represents the reduction of oxidized thioredoxin by thioredoxin reductase (with rate $v_{1}$ ) and reaction (2) represents the reduction of a substrate PSS to PSH with the concomitant oxidation of reduced thioredoxin to oxidized thioredoxin (with rate $v_{2}$ ). Scheme I can be described with the following equations:

$$
\begin{aligned}
& v_{1}=k_{1} \cdot N A D P H \cdot \operatorname{Tr} x S S \\
& v_{2}=k_{2} \cdot \operatorname{Tr} x S H \cdot p s s
\end{aligned}
$$

The analytical steady-state solution for such a single cycle redoxin system with mass action kinetics for redoxin oxidation and reduction was described previously [10]. The steady-state flux, $J$, through the thioredoxin oxidation reaction, can thus be described as follows:

$$
\begin{aligned}
& J=v_{1}=v_{2}=\frac{\left(k_{1} \cdot N A D P H \cdot T r x_{t o t a l}\right) \cdot p s s}{\frac{k_{1}}{k_{2}} N A D P H+p s s} \\
& =\frac{\left(k_{1} k_{2} \cdot N A D P H \cdot T r x_{t o t a l}\right) \cdot p s s}{k_{1} \cdot N A D P H+k_{2} \cdot p s s}
\end{aligned}
$$

where $k_{1}$ is rate constant for the NADPH-dependent reduction of thioredoxin, $k_{2}$ is rate constant for oxidation of thioredoxin by substrate PSS, and $\operatorname{Tr} x_{\text {total }}$ is the moiety sum of the reduced and oxidized thioredoxin concentrations. Equation (5) has the same form as the MichaelisMenten equation with an apparent $V_{\max }$ described by $k_{1} \cdot N A D P H \cdot \operatorname{Tr} x_{\text {total }}$, an apparent $k_{\text {cat }}$ described by $k_{1} \cdot N A D P H$ and an apparent $K_{\mathrm{m}}$ described by $k_{1} \cdot N A D P H / k_{2}$.

As described previously [10], with increases in substrate concentration PSS, the flux through the thioredoxin oxidation reaction will saturate as the thioredoxin reduction reaction becomes limiting (equation (5)). Given that thioredoxin has multiple substrates within the cell [3], these results imply that a substantial increase in the concentration of these substrates, individually or collectively, could result in the apparent saturation of all substrate reduction reactions by the thioredoxin system. Secondly, the maximum flux through the thioredoxin system is determined by the concentration and activity of thioredoxin reductase $\left(k_{1}\right)$, the NADPH concentration, and the total thioredoxin concentration $\left(\operatorname{Tr} x_{\text {total }}\right)$. These molecules, together with the thioredoxin redox ratio, are therefore key indicators of the state of the thioredoxin system. The apparent $K_{\mathrm{m}}$ of the thioredoxin system is determined by the relative rates of thioredoxin oxidation and reduction and the NADPH concentration (equation (5)), and if the term $k_{1} \cdot N A D P H$ is several fold higher than the term $k_{2} \cdot p s s$, then the rate of PSS reduction is linear with respect to PSS concentration $\left(J \approx k_{2} \cdot \operatorname{Tr} x_{\text {total }} \cdot p s s\right.$, see equation (6)). 
To confirm these analytical results a core model based on Scheme I with Michaelis-Menten kinetics for the thioredoxin reductase and mass action kinetics for the thioredoxin oxidation reactions [10] was analyzed (Table 2). All parameters in the model including the total thioredoxin concentration were initially set to one. The concentration of the thioredoxin redox partner PSS was varied over a hundred fold range and the effect on the flux through the system determined at differing concentrations of a given parameter (Figure 3). In agreement with the analytical solution for the system (equation (5)), increasing the concentrations of NADPH and thioredoxin reductase increased the maximal attainable flux through the thioredoxin system (Figure 3A-B). Further, with increases in these concentrations, higher concentrations of PSS were required to saturate the system (i.e. the apparent $K_{\mathrm{m}}$ for PSS increased (Figure 3A-B)). The activity of thioredoxin reductase is therefore a crucial determinant of the kinetic profile of thioredoxin oxidation reactions.

Changes in the total (oxidized and reduced) thioredoxin concentration also affected the fluxes and kinetic profiles of thioredoxin-dependent reactions in the thioredoxin system (Figure 3C). With increases in this concentration, the maximal flux through the thioredoxin

Table 2 Kinetic parameters and metabolite concentrations used in core models of the $E$. coli thioredoxin system

\begin{tabular}{|c|c|}
\hline & Value \\
\hline Metabolites & $(\mu \mathrm{M})$ \\
\hline $\mathrm{NADPH}$ & 1 \\
\hline NADP & 1 \\
\hline TrxSH & 0.5 \\
\hline Trxss & 0.5 \\
\hline PSS & 1 \\
\hline PSH & 1 \\
\hline RSS & 1 \\
\hline RSH & 1 \\
\hline \multicolumn{2}{|l|}{ Thioredoxin } \\
\hline \multicolumn{2}{|l|}{ reductase } \\
\hline [TR] & $1 \mu \mathrm{M}$ \\
\hline$k_{\text {cat }}$ & $1 \mathrm{~s}^{-1}$ \\
\hline$K_{\text {nadph }}$ & $1 \mu \mathrm{M}$ \\
\hline$K_{\text {trxss }}$ & $1 \mu \mathrm{M}$ \\
\hline \multicolumn{2}{|l|}{ PSS reduction } \\
\hline$k_{2}$ & $1 \mu \mathrm{M}^{-1} \mathrm{~s}^{-1}$ \\
\hline \multicolumn{2}{|l|}{ RSS reduction } \\
\hline$k_{3}$ & $1 \mu \mathrm{M}^{-1} \mathrm{~s}^{-1}$ \\
\hline
\end{tabular}

Core models of the thioredoxin system based on Schemes I and II were created using Michaelis-Menten kinetics for thioredoxin reductase and mass action kinetics for the reduction of PSS and RSS by thioredoxin. To simplify the analysis, all reaction parameters in these models were set to one. The parameters listed in this table were used in the generation of Figures 3 and 5 . system increased but the system rapidly saturated at comparatively lower concentrations of PSS (cf. Figure 3A-B).

\section{Ultrasensitivity responses in the thioredoxin system}

Zero-order ultrasensitive responses are typically generated by enzymatically linked moiety-conserved cycles in which at least one of the converter enzymes is saturated by its substrate [26]. However, in our model of the $E$. coli thioredoxin system, all the reactions were coupled to a single thioredoxin redox cycle and most of the enzymatic reactions were not under zero-order conditions (Table 1). Other ultrasensitive kinetic motifs such as positive cooperativity and multi-step activation were also not evident in our kinetic model.

To determine the kinetic mechanism underlying the ultrasensitive changes in the concentration of thioredoxin with changes in the thioredoxin reductase concentration (Figure 2B), the rates in each of the thioredoxin oxidation reactions in the model where were sequentially set to zero and the effect on the ultrasensitive change in the thioredoxin concentration monitored. This analysis revealed that this effect was mediated primarily by the coupling of the thioredoxin redox cycle to the Tpx redox cycle (data not shown), with the kinetic parameters of the Tpx redox cycle being critical to this response (Figure 4).

To investigate the mechanism behind this behaviour, a core model comprising just the thioredoxin and Tpx redox cycles with realistic kinetic parameters and expressions was developed. The ratio of the second order rate constants for Tpx reduction and oxidation were varied (i.e. $k_{\mathrm{H} 2 \mathrm{O} 2} / k_{\text {trxsh }}$, Table 1 ) and the effect of the changes in the thioredoxin and Tpx redox cycles monitored in the model (Figure 4). Decreases in the $k_{\mathrm{H} 2 \mathrm{O} 2} / k_{\text {trxsh }}$ ratio resulted in steeper changes in the reduced thioredoxin and oxidized Tpx concentrations (Figure 4A, D) showing that the ultrasensitive response can be rationalized by considering the effects of increases in the thioredoxin reductase concentration on the Tpx moiety pool. With increases in the thioredoxin reductase concentration, the steady state rates of all the reactions in the system would be expected to increase until the thioredoxin redox cycle saturated (Figure 2A-B, see [10] for a detailed explanation). However, as the activity of hydrogen peroxide reduction reaction is far smaller than thioredoxin reduction reaction in Tpx redox cycle (i.e. $k_{\mathrm{H} 2 \mathrm{O} 2}<<k_{\text {trxsh }}$, Table 1 ), these increases would trigger a relatively abrupt distribution of the oxidized Tpx pool into the reduced state (consider Figure $4 \mathrm{C}, \mathrm{k}_{5} / \mathrm{k}_{6}=0.010$ ). This in turn would trigger an abrupt distribution of the thioredoxin pool into the reduced state to keep the Tpx reduction 

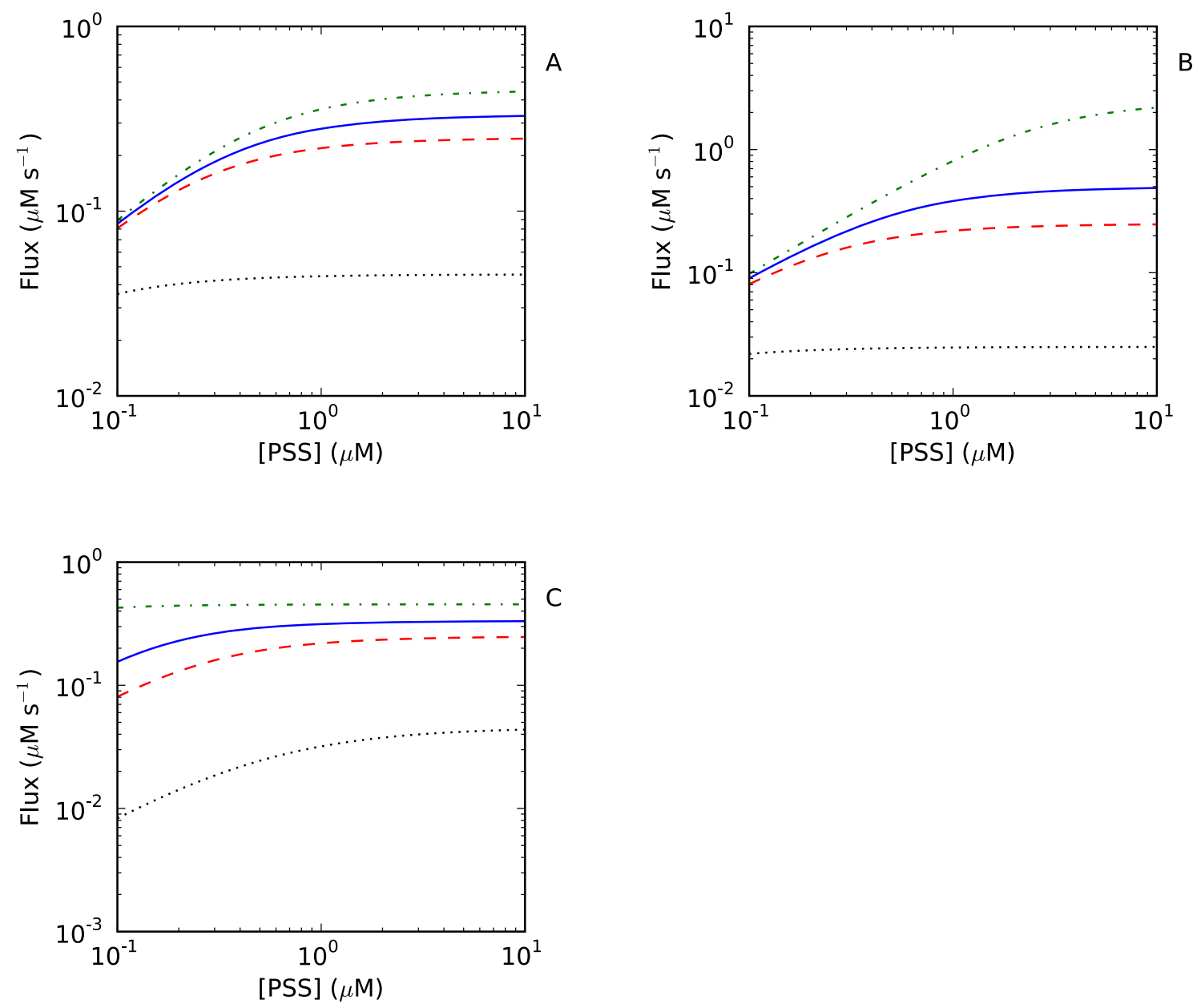

Figure 3 The effect of changes in the concentration of the components of the thioredoxin system on the kinetic profile of the system. In a kinetic model of the thioredoxin system, the concentrations of NADPH (A), thioredoxin reductase (B) and thioredoxin (C) were changed over the range 0.1 (black, ...), 1 (red, -), 2 (blue, -) and 10 (green, --) and the response of the flux through the thioredoxin reductase reaction towards changes in the PSS concentration monitored. Parameters were as in Table 2, except where indicated otherwise. This figure was generated using 'Logic_Figure 3.psc' (Additional file 3). A SBML version of this model ('Logic_Figure 3.xml') is available as Additional file 7.

reaction at steady state, leading to an apparently ultrasensitive response. Thus, the kinetics of Tpx redox cycle determines the ultrasensitive response of the thioredoxin cycle. The hydrogen peroxide concentration used in the realistic model (Table 1) represents the basal hydrogen peroxide concentration in a wild type E. coli cell [27] and this ultrasensitive effect therefore occurs independently of other hydrogen peroxide scavengers such as AhpC [28].

\section{Interconnectivity between thioredoxin-dependent processes}

In the redox circuit model of redoxin systems (Figure 1) thioredoxin-dependent reactions are considered to be essentially independent of each other. In our model of the thioredoxin system on the other hand, changes in the activity of some reactions clearly affected the fluxes of other reactions (Figure 2). This connectivity between thioredoxin-dependent pathways has been demonstrated in mammalian cells. In these cells, thioredoxin is responsible for apoptosis signal-regulating kinase 1 (Ask1) signalosome inactivation and, together with 2 Cys peroxiredoxins [16], hydrogen peroxide reduction. The oxidation of thioredoxin due to increases in the intracellular hydrogen peroxide levels triggers Ask1 signalosome activation and apoptosis [29-31] showing that these pathways do affect each other.

To describe this connectivity between thioredoxindependent pathways more precisely, a simplified scheme describing the oxidation of thioredoxin by two 

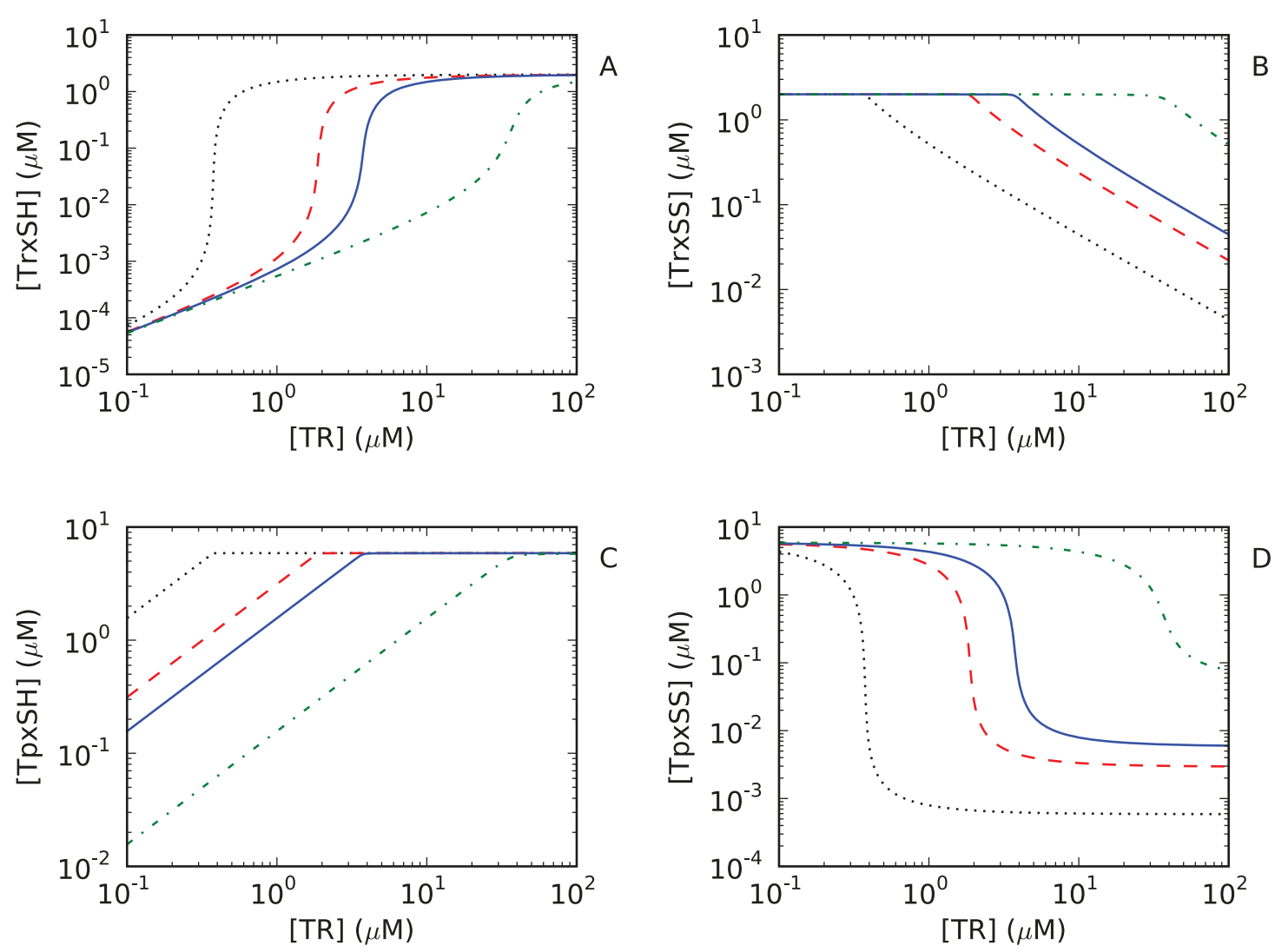

Figure 4 Ultrasensitive changes in the steady state concentrations of the redox couples in the thioredoxin and Tpx redox cycles are dependent on the kinetics of the Tpx redox cycle. In each of these simulations, the ratio of the second order rate constants for Tpx oxidation and reduction (i.e. $k_{\mathrm{H} 2 \mathrm{O} 2} / k_{\text {trxsh, }}$ Table 1) were varied from 0.015 (black, ...), 0.05 (red, - ) 0.10 (blue, solid line) to 1.00 (green, ---) and the effect on the steady state concentrations of reduced thioredoxin (TrxSH), oxidized thioredoxin (TrxSS), reduced Tpx (TpxSH) and oxidized Tpx (TpxSS) monitored. Parameters were as in Table 2, except where indicated otherwise. This figure was generated using 'Logic_Figure

2_and_Figure 4.psc' (Additional file 1). A SBML version of this model ('Logic_Figure 2_and_Figure 4.xml') is available as Additional file 5.

substrates and its subsequent reduction by thioredoxin reductase was analyzed:

Scheme II

$$
\begin{aligned}
& N A D P H+\operatorname{Tr} x S S \rightarrow N A D P+\operatorname{Tr} x S H \\
& \operatorname{Tr} x S H+P S S \rightarrow \operatorname{Tr} x S S+P S H \\
& \operatorname{Tr} x S H+R S S \rightarrow \operatorname{Tr} x S S+R S H
\end{aligned}
$$

Equations (7) and (8) were the same as in Scheme I and were described by rates $v_{1}$ and $v_{2}$. Reaction (8) represents an additional thioredoxin oxidation reaction, involving the reduction of $R S S$ to $R S H$ and was described by $v_{3}$. To simplify the analysis, all reactions were described with irreversible mass action kinetics.
Scheme II can be described with the following equations:

$$
v_{1}=k_{1} \cdot \mathrm{NADPH} \cdot \mathrm{Tr} x \mathrm{SS}
$$

$$
v_{2}=k_{2} \cdot \operatorname{Tr} x S H \cdot p s s
$$

$$
v_{3}=k_{3} \cdot \operatorname{TrxSH} \cdot r s S
$$

$$
\operatorname{Tr} x \mathrm{SH}+\operatorname{Tr} x S S=\operatorname{Tr} x_{\text {total }}
$$

$\frac{d \operatorname{Tr} x S H}{d t}=k_{1} \cdot \mathrm{NADPH} \cdot \operatorname{Tr} x S S$

$$
-k_{2} \cdot \operatorname{Tr} x \mathrm{SH} \cdot \mathrm{pss}-k_{3} \cdot \operatorname{Tr} x \mathrm{SH} \cdot \mathrm{rss}
$$


At steady state equation (14) is equal to zero and can be rearranged to yield:

$$
\operatorname{TrxSH}=\frac{k_{1} \cdot N A D P H \cdot \operatorname{Tr} x_{\text {total }}}{k_{1} \cdot N A D P H+k_{2} \cdot p s s+k_{3} \cdot r s s}
$$

Substituting equation (15) into equation (11) and solving yields the following the expression for the steadystate flux through reaction $v_{2}$ :

$$
J_{2}=\frac{\left(k_{1} \cdot N A D P H \cdot T r x_{\text {total }}\right) \cdot p s s}{\left(\frac{k_{1} \cdot N A D P H+k_{3} \cdot r s s}{k_{2}}\right)+p s s}
$$

Equation (16) is similar to the previously described analytical solution for a single cycle redoxin system (equation (5) and see [10]) with an apparent $V_{\max }$ described by $k_{1} \cdot N A D P H \cdot \operatorname{Tr} x_{\text {total }}$ and an apparent $k_{\text {cat }}$ described by $k_{1} \cdot N A D P H$. However, in contrast to equation (5), it includes an additional term $k_{3} \cdot r s s$, that is part of the apparent $K_{\mathrm{m}}$ for reaction $v_{2}$. Using similar reasoning, it can be shown that for a system containing $n$ thioredoxin oxidation reactions with their respective substrates $\left(X S S_{i}\right)$, the flux through $v_{2}$ can be described as follows:

$$
J_{2}=\frac{\left(k_{1} \cdot N A D P H \cdot \operatorname{Tr} x_{\text {total }}\right) \cdot p s s}{\left(\frac{k_{1} \cdot N A D P H+\sum_{i=3}^{n} k_{i} \cdot x s s_{i}}{k_{2}}\right)+p s s}
$$

This result shows that the flux through reaction $v_{2}$ is affected by other thioredoxin oxidation reactions. Increases in the redox partner concentrations $\left(X S S_{i}\right)$ of the other thioredoxin-dependent reactions can decrease the flux through a given thioredoxin oxidation reaction. In addition, it would take a higher PSS concentration to saturate $v_{2}$ in the presence of these additional thioredoxin redox partners. In effect, these redox partners act as competitive inhibitors, increasing the apparent $K_{\mathrm{m}}$ for PSS (cf. equation (5) and equation (17)). Finally, in a system with a single thioredoxin oxidation reaction (cf. equation (5)), the ratio of the apparent $k_{\text {cat }} / K_{\mathrm{m}}$ is equal to the second order rate constant for that thioredoxin oxidation reaction [10]. Equations (16-17) show that this relationship no longer holds for a system with more than one thioredoxin oxidation reaction, emphasizing that Michaelis-Menten parameters derived in vitro should be used with caution when making inferences about thioredoxin oxidation reactions in vivo [10], or, preferably, not used at all.
To confirm the analytical solution, a core model of Scheme II with Michaelis-Menten kinetics for the thioredoxin reductase and mass action kinetics for the thioredoxin oxidation reactions [10] was developed (Table 2). The effect of increasing concentrations of RSS on the PSS saturation profile for $v_{2}$ was determined. As predicted by the analytical solution (equation (16)), with increases in the flux through $v_{3}$, the flux through $v_{2}$ decreased for a given PSS concentration (Figure 5A). In effect, reactions $v_{2}$ and $v_{3}$ were competing for the same pool of reduced thioredoxin. Further, as predicted by the analytical solution for

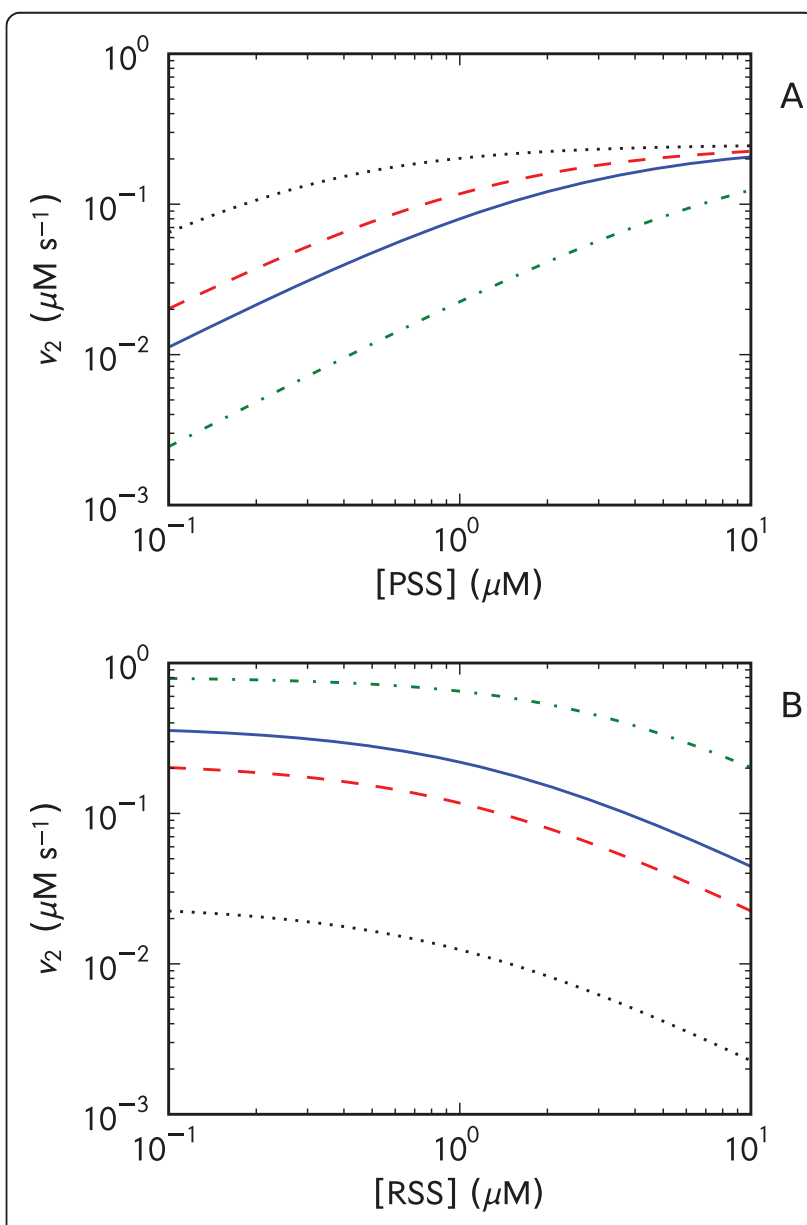

Figure 5 Thioredoxin oxidation reactions can affect each other. In (A), the flux through the thioredoxin-dependent reduction reaction of a substrate (PSS) at varying concentrations of a second thioredoxin substrate (RSS, Scheme II) was monitored in a kinetic model of the thioredoxin system (Scheme II). The concentrations of RSS were 0.1 (black, -.-), 1 (red, -), 2 (blue, -) and 10 (green, --). In (B), the flux through the thioredoxin-dependent reduction of PSS with increasing concentrations of RSS was monitored over a range of thioredoxin reductase concentrations: 0.1 (black, ...), 1 (red, -), 2 (blue, -) and 10 (green, --). Parameters were as in Table 2, except where indicated otherwise. This figure was generated using 'Logic_Figure 5.psc' (Additional file 4). A SBML version of this model ('Logic_Figure 5.xml') is available as Additional file 8. 
the system, increases in the RSS concentration increased the apparent $K_{\mathrm{m}}$ for reaction $v_{2}$. Thus, thioredoxin oxidation reactions can affect the kinetic profile of other thioredoxin oxidation reactions.

Given that the thioredoxin reductase activity plays a key role in the kinetic profile of thioredoxin-dependent reactions (Figure 2A, 3B, equations (16-17)), the effect of increasing concentrations of RSS on the flux through reaction $v_{2}$ was monitored at varying concentrations of thioredoxin reductase (Figure 5B). As described above, with increases in the concentration of RSS, the flux through $v_{2}$ decreased but this effect was more pronounced at lower concentrations of thioredoxin reductase (Figure 5B). A high thioredoxin reductase activity ensured that reduced thioredoxin was not limiting for thioredoxin oxidation reactions and these reactions consequently exerted a smaller effect on each other.

\section{Redox sensitivity and insulation}

The previous analyses demonstrated that all reactions linked to the thioredoxin redox cycle affect each other. However these effects were not equivalent for all reactions involving thioredoxin. In our model of the E. coli thioredoxin system, some reactions appeared to be readily affected by or sensitive to changes in the thioredoxin cycle, whilst other reactions appeared to be relatively unaffected by or insulated from changes to this redox cycle (Figure 2). We analyzed the effects of changes in the thioredoxin concentration on four types of reactions: protein disulfide reduction by thioredoxin, MichaelisMenten and ping-pong enzymatic mechanisms and a thioredoxin-dependent redox cycle.

The reduction of protein disulfides by thioredoxin (Figure 1) was described with the following mass action kinetic expression:

$$
v=k_{1} \cdot \operatorname{Tr} x S H \cdot p s s
$$

This equation shows that the fluxes through thioredoxin-dependent mass action reactions change faithfully with changes in the thioredoxin concentration. Increases in the thioredoxin concentration cause a proportional increase in the flux through this reaction and vice versa, and such reactions are consequently very sensitive to changes in the thioredoxin redox cycle. In our E. coli thioredoxin kinetic model, the fluxes through the protein disulfide and PAPS reduction reactions increased or decreased with corresponding changes in the reduced thioredoxin concentration (Figure 2A-B). This reaction was however not affected by changes in the PAPS and methionine sulfoxide-reductase reactions (Figure 2D-E) as these reactions did not significantly affect the thioredoxin concentration over the concentration ranges tested (result not shown).
Thioredoxin is a substrate for enzymes such as ribonucleotide, methionine sulfoxide and PAPS-reductase [3]. The effect of changes in the thioredoxin concentration on the Michaelis-Menten and ping-pong kinetic mechanisms was analyzed. In these expressions, $a$ represents the concentration of the substrate reduced with reducing equivalents from thioredoxin and $K_{\mathrm{a}}$ represents the binding constant of that substrate to the enzyme. The Michaelis-Menten expression for such a reaction (assuming independent binding of the two substrates to separate sites) is shown below:

$$
v=\frac{V_{\max } \cdot\left(\frac{\operatorname{Tr} x S H}{K_{T r x S H}}\right)\left(\frac{a}{K_{a}}\right)}{\left(1+\frac{\operatorname{TrxSH}}{K_{\operatorname{Tr} x S H}}\right)\left(1+\frac{a}{K_{a}}\right)}
$$

The elasticity expression $[21,22]$ of such a reaction to changes in the thioredoxin concentration is given by:

$$
\varepsilon_{T r x S H}^{v}=\frac{1}{1+\frac{\operatorname{Tr} x S H}{K_{T r x S H}}}
$$

The ping-pong kinetic mechanism for the enzyme-catalyzed reduction of a substrate, $A$, by thioredoxin has the following expression:

$$
v=\frac{V_{\max } \cdot\left(\frac{\operatorname{TrxSH}}{K_{\operatorname{TrxSH} H}}\right)\left(\frac{a}{K_{a}}\right)}{\left(\frac{a}{K_{a}}\right)+\frac{\operatorname{TrxSH}}{K_{T r x S H}}+\left(\frac{\operatorname{TrxSH}}{K_{T r x S H}}\right)\left(\frac{a}{K_{a}}\right)}
$$

The elasticity expression of this reaction to thioredoxin is given by:

$$
\varepsilon_{\text {TrxSH }}^{v}=\frac{\frac{a}{K_{a}}}{\left(\frac{a}{K_{a}}+\frac{\operatorname{Tr} x S H}{K_{T r x S H}}+\frac{a \cdot \operatorname{Tr} x S H}{K_{a} K_{T r x S H}}\right)}
$$

These solutions show that the sensitivity of an enzyme with Michaelis-Menten kinetics to changes in the reduced thioredoxin concentration depends on the thioredoxin concentration and binding constants (equation (20)), whilst ping-pong enzymes are sensitive to the concentrations and binding constants of both substrates (equation (22)).

Thioredoxin reduces a number of proteins such as peroxiredoxins $[32,33]$ which are in turn oxidized by other partners, forming a redox cycle for these proteins (Figure 1). To determine the conditions under which 
such cycles could be insulated or sensitive to changes in the thioredoxin concentration, the following scheme was analyzed:

$$
\begin{aligned}
& \text { Scheme III } \\
& M+\operatorname{TrxS} H \rightarrow M^{\prime}+\operatorname{Tr} x S S \\
& M^{\prime}+C \rightarrow M+C^{\prime}
\end{aligned}
$$

where $M$ is reduced by thioredoxin and described by a mass action expression with a forward rate constant, $k_{1}$ and $M^{\prime}$ is oxidized by $C$ to $M$ and the reaction described by a mass action rate expression with a forward rate constant $k_{2} . M$ and $M^{\prime}$ constitute a moiety conserved cycle with moiety sum, $M_{\mathrm{t}}$. As described for equation (5), the steady-state flux through the the reduction of $C$ by $M^{\prime}$ can be described by the following kinetic expression:

$$
J=\frac{k_{1} \cdot \operatorname{Tr} x S H \cdot M_{\mathrm{t}} \cdot c}{\frac{k_{1}}{k_{2}} \operatorname{Tr} x S H+c}
$$

The response coefficient [34] for this expression with respect to thioredoxin is

$$
R_{T r x S H}^{J}=\frac{c}{\frac{k_{1}}{k_{2}} \operatorname{Tr} x S H+c}
$$

This analysis indicates that if the concentration of the oxidizing substrate for the redox cycle ( $c$, Scheme III) is very low, then equation (26) tends to zero and the cycle is relatively insensitive to changes in the reduced thioredoxin concentration. On the other hand, if the concentration of the oxidizing substrate was to increase (relative to the term $k_{1} / k_{2} \operatorname{Tr} x S H$ ), then the response would approach one indicating that the cycle would be more sensitive to the reduced thioredoxin concentration and therefore the thioredoxin redox cycle. Equation (26) also shows that if the ratio of the reduction and oxidation rate constants for $M$ and $M^{\prime}$ respectively (i.e. $k_{1} / k_{2}$, equation (26)) is very high compared to the concentration of $c$, then the flux through the redox cycle is also relatively insulated from changes in the concentration of reduced thioredoxin. Thus, those cycles with a higher rate of thioredoxin-dependent reduction (cf. equation (23)) compared to oxidation (cf. equation (24)) are less sensitive to changes in the thioredoxin redox cycle. Finally and in agreement with other modeling results (Figure 5B), this equation shows that limiting concentrations of (reduced) thioredoxin increase the response of this cycle to changes in the thioredoxin redox cycle.
In our computational model of the E. coli thioredoxin system (Figure 2), the rate constant for Tpx reduction $\left(3000 \mu{\left.\mathrm{M} . \mathrm{s}^{-1}\right)}\right.$ was significantly greater than the rate

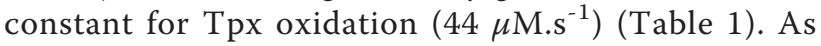
predicted from equation (26), this redox cycle was consequently less sensitive to changes in the thioredoxin redox cycle compared to other thioredoxin oxidation reactions (Figure 2). Further, the comparatively high rate of thioredoxin oxidation by $\mathrm{Tpx}$ also ensured that in the presence of hydrogen peroxide, reducing equivalents from thioredoxin were preferentially used for hydrogen peroxide reduction and that the fluxes of other thioredoxin oxidation reactions were decreased (Figure 2F).

\section{Discussion}

The thioredoxin system appears to be regulated at multiple levels from gene expression $[11,35,36]$ to the cellular metabolism [7,37] level. This, together with large number of thioredoxin-dependent processes [3], suggests a potentially complex network of regulatory interactions. In this paper, we focused on the kinetic regulation of the E. coli thioredoxin system and associated reactions.

Changes in the component concentrations of the thioredoxin system in vitro have resulted in changes to the Michaelis-Menten parameters assigned to thioredoxin [8], whilst changes to concentrations and activities of components of the thioredoxin system in vivo have been associated with distinct physiological changes [3,8,38-42]. These results suggest that the thioredoxin system is adaptable and our analysis confirmed that changes in the system, especially the thioredoxin reductase concentration, can affect the kinetic profiles of thioredoxin oxidation reactions. For example, decreases in the thioredoxin reductase activity decreased the fluxes and caused thioredoxin oxidation reactions to saturate at lower concentrations of their substrates (Figures 2A, 3B). In addition, the fluxes of thioredoxin oxidation reactions affected each other to a greater extent (Figure $5 \mathrm{~B})$. Thioredoxin reductase activity is therefore a key parameter for the function of the thioredoxin system and associated reactions. These results explain why drugs that target this enzyme are so potent $[41,42]$ as inhibition of thioredoxin reductase would not only affect the thioredoxin redox cycle but could trigger systemwide effects on all thioredoxin-dependent reactions (Figure 2A). The viability E. coli and yeast thioredoxin reductase mutants $[3,43]$ does however suggest that the glutathione/glutaredoxin system can adequately compensate for the thioredoxin system in these cells [3].

Despite evidence of cross-talk between thioredoxin pathways in Ask1 signalosome activation [29-31], thioredoxin-dependent reactions and processes have been considered essentially independent of each other in 
redox circuit models of the thioredoxin system (see for example Figures 1, 2 in [3] and Figure 1 in [42]). However, our analysis showed that changes in the thioredoxin cycle which increased or decreased the steady state thioredoxin concentration, affected the fluxes of other thioredoxin oxidation reactions (Figure 2, equations (16-17)). Thioredoxin oxidation reactions are therefore connected to, and can affect each other via the thioredoxin redox cycle. Whilst all thioredoxindependent reactions can, in principle, affect each other, our model of the $E$. coli thioredoxin system showed that these reactions displayed differential sensitivities to changes in the redox cycle, allowing for several modes of kinetic regulation within the system (Figure 2). Thioredoxin-dependent mass action reactions were relatively sensitive to changes in the thioredoxin redox cycle (Figure $2 \mathrm{~A}, \mathrm{~F}$ ), whilst the sensitivity of enzymatic reactions and redox cycles (Scheme II) depended on their individual kinetic parameters (equations (20, 22, 26), Figure $2 \mathrm{~A}, \mathrm{C}, \mathrm{E}, \mathrm{F})$. For example, in response to increasing hydrogen peroxide concentrations, non-specific protein disulfide reduction by thioredoxin was dramatically reduced, whilst the Tpx flux, which is involved in the oxidative stress response, was affected to a lesser degree (Figure 2F). These results suggest that the flux distribution within the thioredoxin system may change dynamically in response to the physiological state of the cell.

In our kinetic model the Tpx redox cycle in particular was insulated from changes that occurred in the thioredoxin redox cycle when compared to other thioredoxin oxidation reactions (Figure 2). Further, the relatively high rate constant for the thioredoxin-dependent reduction of Tpx (Table 1) ensured that hydrogen peroxide reduction was prioritized over protein disulfide, PAPS and methionine sulfoxide reduction (Figure 2F). This finding agrees with other work showing that E. coli metabolic processes are very sensitive to hydrogen peroxide (reviewed in [44]) and the model predicts that the coupling of hydrogen peroxide metabolism to the thioredoxin redox cycle can limit sensitive cellular processes, such as DNA synthesis, under oxidative stress conditions.

An intriguing finding was that the kinetic structure of the Tpx redox cycle and its coupling to the thioredoxin redox cycle, led to ultrasensitive changes in the reduced thioredoxin concentration with changes in the thioredoxin reductase concentration. In turn, these changes resulted in large changes in the fluxes of thioredoxindependent cellular processes (Figures 2A-B). This indicates that the coupling between hydrogen peroxide metabolism and the thioredoxin redox cycle could represent a mechanism to coordinate large changes in the thioredoxin-dependent processes within a cell and that the inhibition of Tpx activity would disrupt this mechanism. Whether this mechanism is utilized in vivo still needs to be determined although the upregulation of thioredoxin reductase in pathological conditions such as cancer [2] suggests that this may represent a mechanism for these cells to effect large changes in their metabolism.

\section{Conclusions}

In keeping with published findings, our analysis shows that the kinetics of the thioredoxin redox cycle allows for a system that is adaptable and, in contrast to other models of the system, connects thioredoxin-dependent processes. This is significant because it shows that the capacity through thioredoxin-dependent pathways depends critically on the concentration of thioredoxin reductase and that the electron circuit approach to modeling the thioredoxin system (Figure 1) is limited. Depending on their kinetics thioredoxin-dependent reactions can show differential sensitivities to changes in the thioredoxin redox cycle, allowing for several modes of kinetic regulation within the system. Taken together, these results indicate that the thioredoxin redox cycle is an analogue device that receives, distributes and coordinates redox signaling between metabolic processes within the cell. This work serves as a good starting point for the experimental analysis of the network properties of the thioredoxin system.

\section{Methods}

\section{Kinetic Modeling}

All kinetic modeling experiments were carried out using the open source Python Simulator for Cellular Systems (PySCeS) modeling software [45]. Three types of models were used for analyzing the thioredoxin system. Models with mass action kinetics for all reactions were used to derive analytical solutions for the thioredoxin system. These solutions were confirmed with core models that contained realistic kinetic expressions for thioredoxin reductase but were parameterized with default parameter sets (i.e. all parameters were set to one). Finally, a realistic kinetic parameter set was used to create a computational model of the E. coli thioredoxin system (described below). To describe the kinetic behavior of the thioredoxin system at the pathway level, core and realistic model outputs were plotted as parameter portraits, which capture the systems-level behavior of a metabolic pathway (for a detailed description and examples see $[21,46]$ ). All models will be made available on the JWS Online database [47] and are available in PySCeS (Additional files 1, 2, 3 and 4) and SBML (Additional files 5, 6, 7 and 8) formats. PySCeS model outputs were confirmed with Copasi [48]. In all reaction schemes species names were capitalized, whilst lower case was used to describe species concentrations. 
Realistic kinetic model of the $E$. coli thioredoxin system A realistic kinetic model of the E. coli thioredoxin system was developed that included a number of thioredoxin-dependent reactions: thioredoxin reductase, methionine sulfoxide reductase, PAPS reductase, Tpx and protein disulfide reduction (Figure 1). The kinetic parameters for the model were obtained from literature and from the BRENDA [49] and CyberCell databases [50] (Table 1). However, the concentration of oxidized disulfides (PSS), methionine sulfoxide (MetSO), methionine sulfoxide reductase ([MsrA]), PAPS and PAPS reductase ([PR]) could not be obtained directly from the literature and were estimated as follows.

To estimate the concentration of oxidized disulfides we used a dataset that identified the redox partners of the thioredoxin system in E. coli [51]. Protein sequences for these redox partners were obtained from Uniprot http://www.uniprot.org/ and the numbers of possible disulfide bridges in these proteins were estimated using the DiANNA web server http://clavius.bc.edu/ clotelab/ DiANNA/[52,53]. The in vivo concentration of these disulfide bridges were then estimated using protein concentrations from the CyberCell database [50] which gave a disulfide concentration of $423 \mu \mathrm{M}$. This value represents complete oxidation of all the disulfides in these redox partners and for the modeling experiments shown here we assumed that $1 \%$ of the target disulfides were oxidized. Simulations of the model were undertaken with higher concentration of oxidized disulfide and the results obtained were in agreement the main findings described above (results not shown).

Under normal cultivation conditions $2 \%$ of methionine in the E. coli proteome is oxidized to methionine sulfoxide [54], although the actual concentration of this methionine sulfoxide is not known. Assuming a total E. coli protein concentration of $250 \mathrm{mg} / \mathrm{ml} \mathrm{[55]} \mathrm{and} \mathrm{an}$ average methionine content in the proteome of $2.9 \%$ [56], we estimated a proteome methionine concentration of $48.3 \mathrm{mM}$ and a methionine sulfoxide concentration of $0.97 \mathrm{mM}$. The intracellular protein concentration of methionine sulfoxide reductase was estimated by taking the ratio of its copy number to the Tpx copy number and multiplying by the intracellular concentration of Tpx [57]. The concentration of Tpx was varied ten-fold during simulations of the model but this did not affect the main findings of the study (results not shown).

PAPS reductase is encoded by $c y s H$ which is part of the cys CDHIJ regulon [58] and its concentration was estimated by taking the ratio of its copy number to the CysI copy number and multiplying by the intracellular concentration of CysI [50]. The concentration of PAPS within $E$. coli was not known but has been shown to vary from 0.07 to $20 \mu \mathrm{M}$ in Saccharomyces cerevisiae depending on the state of the cell $[59,60]$. We used
$0.07 \mu \mathrm{M}$ in this study. While PAPS reductase has a ping-pong kinetic mechanism [12] it was modeled with mass action kinetics (Figures 2A-C, E, F) because our assigned concentration was almost 5 -fold higher than the concentration of its substrate (Table 1). However, to determine the effect of increasing PAPS concentrations on the thiroedoxin system, the PAPS reductase reaction was modeled with ping-pong kinetics (Figure 2D).

\section{Acknowledgements}

Funding for this study was provided by a UKZN Competitive Grant (CSP). The authors would like to thank Dr. Julian Westoll for comments on the manuscript.

\section{Author details}

${ }^{1}$ Discipline of Genetics, University of KwaZulu-Natal, South Africa, Carbis Road, Pietermaritzburg, 3201, South Africa. ${ }^{2}$ Triple-J Group for Molecular Cell Physiology, Department of Biochemistry, Stellenbosch University, Van der Byl Street, Stellenbosch 7600, South Africa. ${ }^{3}$ Centre for Studies in Complexity, Stellenbosch University, Marais Street, Stellenbosch, 7600, South Africa.

\section{Authors' contributions}

CSP conceived the study, performed the kinetic modeling and drafted the manuscript, J-HSH and JMR participated in the kinetic analysis and drafted the manuscript. All authors read and approved the final manuscript.

Received: 20 April 2010 Accepted: 25 January 2011

Published: 25 January 2011

\section{References}

1. Vlamis-Gardikas A: The multiple functions of the thiol-based electron flow pathways of Escherichia coli: Eternal concepts revisited. Biochim Biophys Acta 2008, 1780:1170-1200.

2. Arner ES, Holmgren A: The thioredoxin system in cancer. Semin Cancer Biol 2006, 16:420-426.

3. Toledano MB, Kumar C, Le Moan N, Spector D, Tacnet F: The system biology of thiol redox system in Escherichia coli and yeast: differential functions in oxidative stress, iron metabolism and DNA synthesis. FEBS Lett 2007, 581:3598-3607.

4. Holmgren A, Bjornstedt M: Thioredoxin and thioredoxin reductase. Methods Enzymol 1995, 252:199-208.

5. Arner ES, Holmgren A: Physiological functions of thioredoxin and thioredoxin reductase. Eur J Biochem 2000, 267:6102-6109.

6. Trotter EW, Grant CM: Non-reciprocal regulation of the redox state of the glutathione-glutaredoxin and thioredoxin systems. EMBO Rep 2003, 4:184-188

7. Kemp M, Go YM, Jones DP: Nonequilibrium thermodynamics of thiol/ disulfide redox systems: a perspective on redox systems biology. Free Radic Biol Med 2008, 44:921-937.

8. Holmgren A: Reduction of disulfides by thioredoxin. Exceptional reactivity of insulin and suggested functions of thioredoxin in mechanism of hormone action. J Biol Chem 1979, 254:9113-9119.

9. Zahedi Avval F, Holmgren A: Molecular mechanisms of thioredoxin and glutaredoxin as hydrogen donors for mammalian S-phase ribonucleotide reductase. J Biol Chem 2009, 284:8233-8240.

10. Pillay CS, Hofmeyr JH, Olivier BG, Snoep JL, Rohwer JM: Enzymes or redox couples? The kinetics of thioredoxin and glutaredoxin reactions in a systems biology context. Biochem J 2009, 417:269-275

11. Potamitou A, Holmgren A, Vlamis-Gardikas A: Protein levels of Escherichia coli thioredoxins and glutaredoxins and their relation to null mutants, growth phase, and function. J Biol Chem 2002, 277:18561-18567.

12. Boschi-Muller S, Azza S, Branlant G: E. coli methionine sulfoxide reductase with a truncated $\mathrm{N}$ terminus or $\mathrm{C}$ terminus, or both, retains the ability to reduce methionine sulfoxide. Protein Sci 2001, 10:2272-2279.

13. Boschi-Muller S, Olry A, Antoine M, Branlant G: The enzymology and biochemistry of methionine sulfoxide reductases. Biochim Biophys Acta 2005, 1703:231-238. 
14. Lillig CH, Prior A, Schwenn JD, Aslund F, Ritz D, Vlamis-Gardikas A, Holmgren A: New thioredoxins and glutaredoxins as electron donors of 3'- phosphoadenylylsulfate reductase. J Biol Chem 1999, 274:7695-7698.

15. Baker LM, Poole LB: Catalytic mechanism of thiol peroxidase from Escherichia coli. Sulfenic acid formation and overoxidation of essential CYS61. J Biol Chem 2003, 278:9203-9211.

16. Winterbourn CC, Hampton MB: Thiol chemistry and specificity in redox signaling. Free Radic Biol Med 2008, 45:549-561.

17. Ogusucu R, Rettori D, Munhoz DC, Netto LE, Augusto O: Reactions of yeast thioredoxin peroxidases I and II with hydrogen peroxide and peroxynitrite: rate constants by competitive kinetics. Free Radic Biol Med 2007, 42:326-334.

18. Parsonage D, Karplus PA, Poole LB: Substrate specificity and redox potential of AhpC, a bacterial peroxiredoxin. Proc Natl Acad Sci USA 2008, 105:8209-8214.

19. Sayed AA, Williams DL: Biochemical characterization of 2-Cys peroxiredoxins from Schistosoma mansoni. J Biol Chem 2004, 279:26159-26166.

20. Johnson RM, Goyette G Jr, Ravindranath Y, Ho YS: Hemoglobin autoxidation and regulation of endogenous $\mathrm{H} 2 \mathrm{O} 2$ levels in erythrocytes. Free Radic Biol Med 2005, 39:1407-1417.

21. Hofmeyr JS, Cornish-Bowden A: Regulating the cellular economy of supply and demand. FEBS Lett 2000, 476:47-51.

22. Hofmeyr JH: Metabolic regulation: a control analytic perspective. $J$ Bioenerg Biomembr 1995, 27:479-490.

23. Bersani NA, Merwin JR, Lopez NI, Pearson GD, Merrill GF: Protein electrophoretic mobility shift assay to monitor redox state of thioredoxin in cells. Methods Enzymol 2002, 347:317-326.

24. Derman Al, Beckwith J: Escherichia coli alkaline phosphatase localized to the cytoplasm slowly acquires enzymatic activity in cells whose growth has been suspended: a caution for gene fusion studies. J Bacteriol 1995, 177:3764-3770.

25. Stewart EJ, Aslund F, Beckwith J: Disulfide bond formation in the Escherichia coli cytoplasm: an in vivo role reversal for the thioredoxins. EMBO J 1998, 17:5543-5550.

26. Goldbeter A, Koshland DE Jr: Ultrasensitivity in biochemical systems controlled by covalent modification. Interplay between zero-order and multistep effects. J Biol Chem 1984, 259:14441-14447.

27. Seaver LC, Imlay JA: Hydrogen peroxide fluxes and compartmentalization inside growing Escherichia coli. J Bacteriol 2001, 183:7182-7189.

28. Seaver LC, Imlay JA: Alkyl hydroperoxide reductase is the primary scavenger of endogenous hydrogen peroxide in Escherichia coli. J Bacteriol 2001, 183:7173-7181.

29. Nadeau PJ, Charette SJ, Toledano MB, Landry J: Disulfide Bond-mediated multimerization of Ask1 and its reduction by thioredoxin-1 regulate $\mathrm{H}(2)$ $\mathrm{O}$ (2)-induced c-Jun $\mathrm{NH}(2)$-terminal kinase activation and apoptosis. $\mathrm{Mol}$ Biol Cell 2007, 18:3903-3913.

30. Liu H, Zhang H, lles KE, Rinna A, Merrill G, Yodoi J, Torres M, Forman HJ: The ADP-stimulated NADPH oxidase activates the ASK-1/MKK4/JNK pathway in alveolar macrophages. Free Radic Res 2006, 40:865-874.

31. Fujino G, Noguchi T, Takeda K, Ichijo H: Thioredoxin and protein kinases in redox signaling. Semin Cancer Biol 2006, 16:427-435.

32. Janssen-Heininger $\mathrm{YM}$, Mossman BT, Heintz NH, Forman $\mathrm{HJ}$, Kalyanaraman B, Finkel T, Stamler JS, Rhee SG, van der Vliet A: Redox-based regulation of signal transduction: principles, pitfalls, and promises. Free Radic Biol Med 2008, 45:1-17.

33. Rhee SG, Chae HZ, Kim K: Peroxiredoxins: a historical overview and speculative preview of novel mechanisms and emerging concepts in cell signaling. Free Radic Biol Med 2005, 38:1543-1552.

34. Fell D: Understanding the control of metabolism London: Portland Press; 1997.

35. Miranda-Vizuete A, Rodriguez-Ariza A, Toribio F, Holmgren A, Lopez-Barea J, Pueyo C: The levels of ribonucleotide reductase, thioredoxin, glutaredoxin 1, and GSH are balanced in Escherichia coli K12. J Biol Chem 1996, 271:19099-19103.

36. Prieto-Alamo MJ, Jurado J, Gallardo-Madueno R, Monje-Casas F, Holmgren A, Pueyo C: Transcriptional regulation of glutaredoxin and thioredoxin pathways and related enzymes in response to oxidative stress. J Biol Chem 2000, 275:13398-13405

37. Jones DP: Radical-free biology of oxidative stress. Am J Physiol Cell Physiol 2008, 295:C849-868.
38. Kaimul AM, Nakamura H, Masutani H, Yodoi J: Thioredoxin and thioredoxin-binding protein-2 in cancer and metabolic syndrome. Free Radic Biol Med 2007, 43:861-868.

39. Singh K, Kang PJ, Park HO: The Rho5 GTPase is necessary for oxidantinduced cell death in budding yeast. Proc Natl Acad Sci USA 2008, 105:1522-1527.

40. Cox AG, Brown KK, Arner ES, Hampton MB: The thioredoxin reductase inhibitor auranofin triggers apoptosis through a Bax/Bak-dependent process that involves peroxiredoxin 3 oxidation. Biochem Pharmacol 2008, 76:1097-1109.

41. Lu J, Chew EH, Holmgren A: Targeting thioredoxin reductase is a basis for cancer therapy by arsenic trioxide. Proc Natl Acad Sci USA 2007, 104:12288-12293.

42. Powis G, Kirkpatrick DL: Thioredoxin signaling as a target for cancer therapy. Curr Opin Pharmacol 2007, 7:392-397.

43. Fuchs J: Isolation of an Escherichia coli mutant deficient in thioredoxin reductase. J Bacteriol 1977, 129:967-972

44. Imlay JA: Cellular defenses against superoxide and hydrogen peroxide. Annu Rev Biochem 2008, 77:755-776.

45. Olivier BG, Rohwer JM, Hofmeyr JH: Modelling cellular systems with PySCeS. Bioinformatics 2005, 21:560-561.

46. du Preez FB, Conradie R, Penkler GP, Holm K, van Dooren FL, Snoep JL: A comparative analysis of kinetic models of erythrocyte glycolysis. J Theor Biol 2008, 252:488-496.

47. Olivier BG, Snoep JL: Web-based kinetic modelling using JWS Online. Bioinformatics 2004, 20:2143-2144.

48. Hoops S, Sahle S, Gauges R, Lee C, Pahle J, Simus N, Singhal M, Xu L, Mendes P, Kummer U: COPASI-a COmplex PAthway SImulator. Bioinformatics 2006, 22:3067-3074.

49. Chang A, Scheer M, Grote A, Schomburg I, Schomburg D: BRENDA, AMENDA and FRENDA the enzyme information system: new content and tools in 2009. Nucleic Acids Res 2009, 37:D588-592.

50. Sundararaj S, Guo A, Habibi-Nazhad B, Rouani M, Stothard P, Ellison M, Wishart DS: The CyberCell Database (CCDB): a comprehensive, selfupdating, relational database to coordinate and facilitate in silico modeling of Escherichia coli. Nucleic Acids Res 2004, 32:D293-295.

51. Leichert $\mathrm{LI}$, Jakob U: Protein thiol modifications visualized in vivo. PLoS Biol 2004, 2:e333.

52. Ferre F, Clote P: DiANNA 1.1: an extension of the DiANNA web server for ternary cysteine classification. Nucleic Acids Res 2006, 34:W182-185.

53. Ferre F, Clote P: DiANNA: a web server for disulfide connectivity prediction. Nucleic Acids Res 2005, 33:W230-232.

54. Rosen H, Klebanoff SJ, Wang Y, Brot N, Heinecke JW, Fu X: Methionine oxidation contributes to bacterial killing by the myeloperoxidase system of neutrophils. Proc Natl Acad Sci USA 2009, 106:18686-18691.

55. Zimmerman SB, Trach SO: Estimation of macromolecule concentrations and excluded volume effects for the cytoplasm of Escherichia coli. $J \mathrm{Mol}$ Biol 1991, 222:599-620.

56. Neidhardt FC, Umbarger HE, Eds: Chemical composition of Escherichia coli. 2 edition. Washington, D.C.: ASM Press; 1996.

57. Link AJ, Robison K, Church GM: Comparing the predicted and observed properties of proteins encoded in the genome of Escherichia coli K-12. Electrophoresis 1997, 18:1259-1313.

58. Tei H, Murata K, Kimura A: Molecular cloning of the cys genes (cysC, cysD, cysH, cysl, cysJ, and cysG) responsible for cysteine biosynthesis in Escherichia coli K-12. Biotechnol Appl Biochem 1990, 12:212-216.

59. Murguia JR, Belles JM, Serrano R: The yeast HAL2 nucleotidase is an in vivo target of salt toxicity. J Biol Chem 1996, 271:29029-29033.

60. Jakubowski H, Goldman E: Methionine-mediated lethality in yeast cells at elevated temperature. J Bacteriol 1993, 175:5469-5476.

61. Ishii N, Nakahigashi K, Baba T, Robert M, Soga T, Kanai A, Hirasawa T, Naba M, Hirai K, Hoque A, Ho PY, Kakazu Y, Sugawara K, Igarashi S, Harada S, Masuda T, Sugiyama N, Togashi T, Hasegawa M, Takai Y, Yugi K, Arakawa K, Iwata N, Toya Y, Nakayama Y, Nishioka T, Shimizu K, Mori H, Tomita M: Multiple high-throughput analyses monitor the response of $\mathrm{E}$. coli to perturbations. Science 2007, 316:593-597.

62. Chinn PC, Pigiet V, Fahey RC: Determination of thiol proteins using monobromobimane labeling and high-performance liquid chromatographic analysis: application to Escherichia coli thioredoxin. Anal Biochem 1986, 159:143-149. 
63. Gleason FK, Lim CJ, Gerami-Nejad M, Fuchs JA: Characterization of Escherichia coli thioredoxins with altered active site residues. Biochemistry 1990, 29:3701-3709.

64. Williams CHJ: Flavin-Containing Dehydrogenases New York: Academic Press; 1976.

doi:10.1186/1752-0509-5-15

Cite this article as: Pillay et al:: The logic of kinetic regulation in the thioredoxin system. BMC Systems Biology 2011 5:15.

Submit your next manuscript to BioMed Central and take full advantage of:

- Convenient online submission

- Thorough peer review

- No space constraints or color figure charges

- Immediate publication on acceptance

- Inclusion in PubMed, CAS, Scopus and Google Scholar

- Research which is freely available for redistribution

Submit your manuscript at www.biomedcentral.com/submit
() Biomed Central 